\title{
Construction of "654" Sending-teaching-to-the-Countryside Training Mode
}

\author{
Jingmei Yang
}

School of mathematics and statistics, Qujing Normal University, Qujing, Yunnan

421327416@qq.com

Keywords: Sending-teaching-to-the-countryside; Training mode;

\begin{abstract}
The task of the National Training Program mainly consists of two stages, i.e. Intensive Training and Sending-Teaching-to-the-Countryside Training. Through two years of practical exploration, the team has develop the "654"Sending-teaching-to-the-Countryside Training mode, namely six steps, five levels and four dockings. The implementation process is divided into four sections: setting up a training team, six-step advanced guidance, construction of five-level management system and seamless four-party-docking collaboration. The early-stage accurate demand research, coupled with the strict monitoring on the implementation process ensures the quality and effectiveness of teaching-sending. Practice shows that the application of "654" teaching-sending mode has promoted the individual professional development of teachers, the transformation of teachers' training concept, the effective implementation of "school-based training" and the co-growth of the trainers.
\end{abstract}

The new round of national training programs is being carried out in full swing. The task of national training programs undertaken by our school mainly consists of two stages: Intensive Training and Sending-teaching-to-the-countryside Training. During the Intensive Training stage, the "Thematic Training" mode has achieved initial success. That is, each period of training is designed with a problem-oriented thematic course and each thematic course has a corresponding topic. According to the logical system of "problem entry-goal orienting-theoretical support-method support-case analysis-practice test-result display", the topics are designed from the four dimensions of "cognition, theoretical methods, practical application and reflection", and the training objectives are achieved specifically through exploration of four topics, solution of eight sub-problems, and then the practical teaching link in the heterogeneous form for the same course. From September 2015 to September 2017, the team directed and developed a total of 5 thematic courses, each of which consists of several special topics, and each of the special topics includes: brief introduction, special lecture, special courseware, micro class, cases and related resources. Every training was summarized as a course resource package, which can be used as materials for sending teaching to the countryside and subsequent trainings. There are a total of 5 resource packages.

After the Intensive Training, trainers from all counties will conduct "sending teaching to the countryside", that is, to radiate the knowledge and the training mode learned from the intensive training to the front-line teachers in townships and rural areas. Through two years of practice, the team has developed the "654"Sending-teaching-to-the-Countryside Training mode, namely six steps, five levels and four-party-docking. Six Steps means the teaching-sending will be carried out by six steps in the sending teaching activities of different subjects, and the six steps include: demand research to find problems; demonstration diagnosis to determine the theme; intensive training in colleges and universities to enhance the theory; school-based training to produce high-quality classes, results display to bring forth the outstanding ones; and feedback to improve the guidance. Five Levels refers to provincial-level; colleges and universities; county-level; township centers; combined village-level primary schools and teaching spots. The provincial department of education co-ordinates arrangements for the tasks of colleges and universities, colleges and universities carry out the county-level guidance-type teaching-sending, the county-level departments of education carry out the demonstrative township sending teaching, and the township center schools carry out the discussion-base sending teaching to combined village-level primary schools and teaching spots. 
Four-party-docking means that the Continuing Education Center, the county-level sending teaching team, the township-level sending teaching unit undertaking the training and the front-line primary schools will achieve seamless docking in each sending-teaching-to-the-countryside activity. The "654" Sending-Teaching-to-the-Countryside Training Mode can promote the rural teachers to achieve practicing in leading, enhancing in practice, developing in enhancement, and realizing the objectives in development, thus effectively enhancing the implementation ability of classes and improving the quality of education and teaching.

\section{Implementation Process}

\subsection{Setting up the training team}

The county-level educational bureau directors direct the activity personally, the deputy directors are in charge of deployment, and the teacher training schools are responsible for the implementation. Before sending teaching to the countryside, outstanding teachers are selected within the county to set up a training team, who will attend the intensive training in local colleges and universities. The learning quality of the trainees will be strictly monitored to ensure the quality of their training. Relying on the county-level training team, the college and university resources will be integrated. Based on which, a total of four training-sending activities will be carried out per year, and the training duration of each subject will not be less than eight days. The training contents include special topic lectures, demonstration classes and review classes.

\subsection{Providing advanced guidance by six steps}

The Six Steps are developed through detailing on the basis of the National Training Program, combined with the actual situation. The Continuing Education Center of the project county sets up a leading group, to provide step-by-step guidance for the teaching-sending activities, and perform a full-course follow-up. The specific process is: demand research - the combination of personality and commonalities to identify problems; demonstration diagnosis - the combination of phenomena and essence, to determine the theme; intensive training - to study training skills and improve the theory level; school-based training - the combination of useful contents and commonly used contents, to solve the problem; demonstration of results - the combination of normal and demonstration, to build high-quality products; and the combination of feedback information and reflection, to form concepts. The first step to implement the Sending-teaching-to-the-countryside is the demand research to find problems, which is very important. It needs the team to develop an accurate list of research elements in an innovative way in practice in order to the sending-teaching-to-the-countryside activities are targeted and effective.

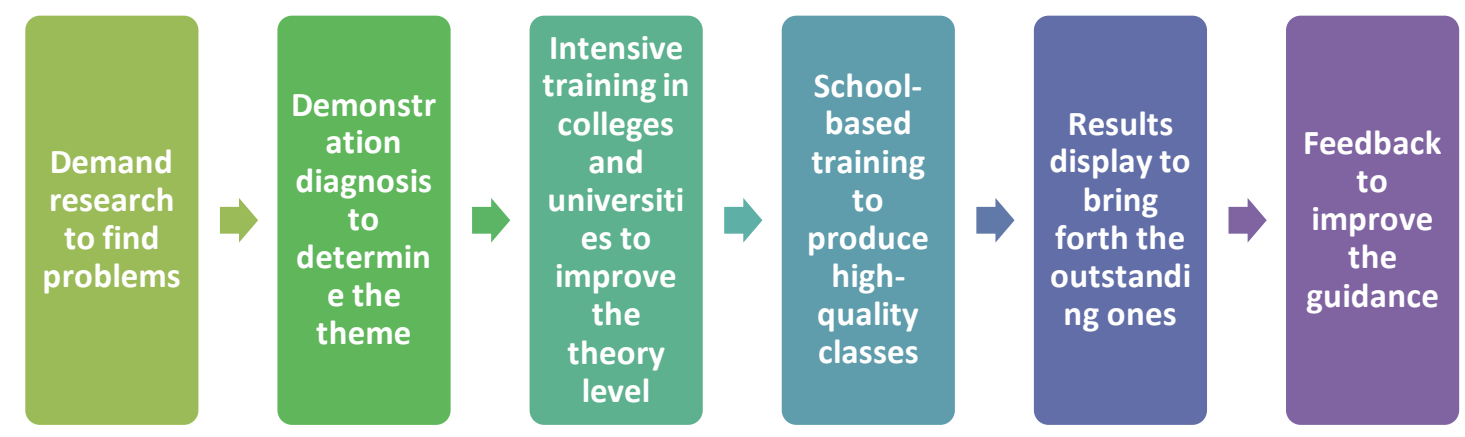

\subsection{Constructing the Five-level management system}

To carry out the five-level teaching-sending with the task-driven approach, relying on the provincial-level, colleges and universities, county-level, township-level and front-line school 
training teams. From 2015 to 2017, the team cooperated with local colleges and universities to complete five sending-training-to-the-countryside activities. The county-level training-sending teams went to all the central primary schools of all rural areas of the whole county to carry out the full-coverage research teaching-sending activities, including more than 80 grinding and studying classes, over 60 demonstration classes and heterogeneous classes and more than 30 wonderful lectures. A total of more than 700 teachers attended the training and have benefited from the same. The backbone teachers of township-level central schools and combined village-level primary schools invited the county-level cooperation teams to send trainings to the teaching spots for more than 20 times. The trainee teachers wrote more than 1,000 training logs, organized 22 training briefings, collected 57volumes of information and sorted out more than 30 boxes of files. The five-level teaching-sending achieved full coverage of the schools within the county and within all township schools, enhancing the effectiveness of sending-teaching-to-the-countryside.

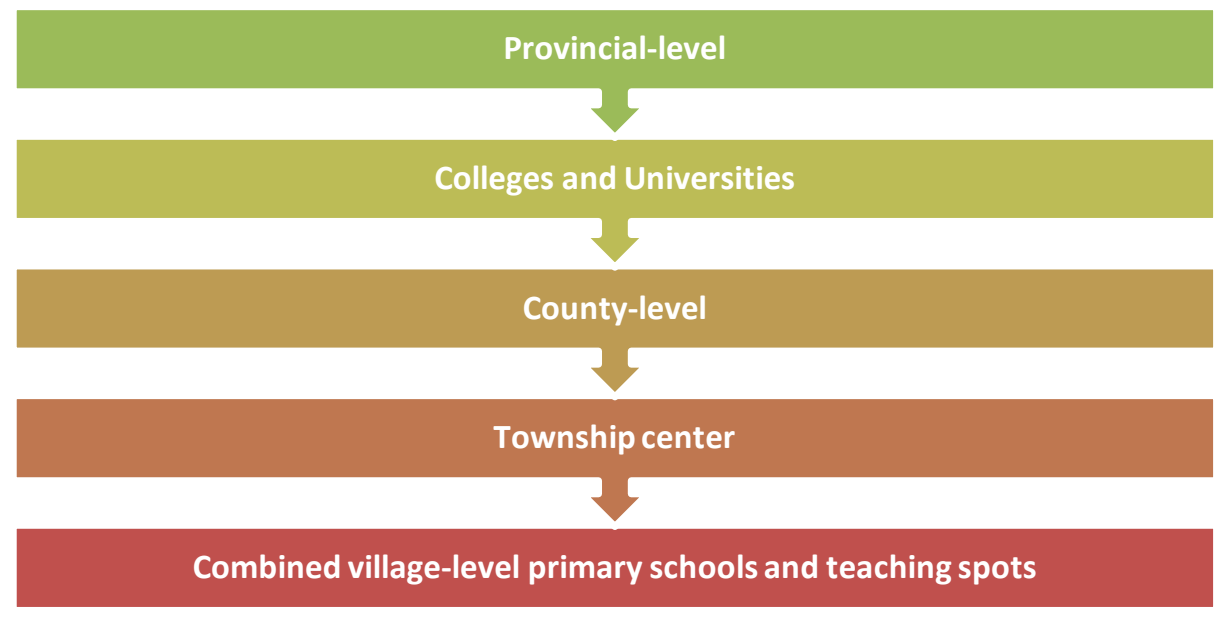

\subsection{Seamless Four-docking Collaboration}

Across a county, each township central school is taken as the unit to set up the regional collaborators for the teaching sending activities. Before the teaching sending, the four-part-docking program will be implemented among the Continuing Education Center of the county, the regional collaborator of the county, the township-level sending teaching unit undertaking the training, and the front-line primary and secondary schools. There are a total of 15 docking items in the program, including: demand research, teaching-sending topics, training objects, training objectives, teaching-sending time, teaching-sending environment, teaching-sending mode, grinding class schedule, demonstration class schedule, expert lectures, discussion class grouping, discussion class location, accommodation, safety management, and expected effects. After that, a variety of trainings such as special topic lectures, teaching demonstrations, heterogeneous classes, exchange and interaction, on-site guidance, results display and summary \& promotion will be carried out according to the trainees' demands, forming a "six-in-one" regional and regional sending-teaching-to-the-countryside training system. 


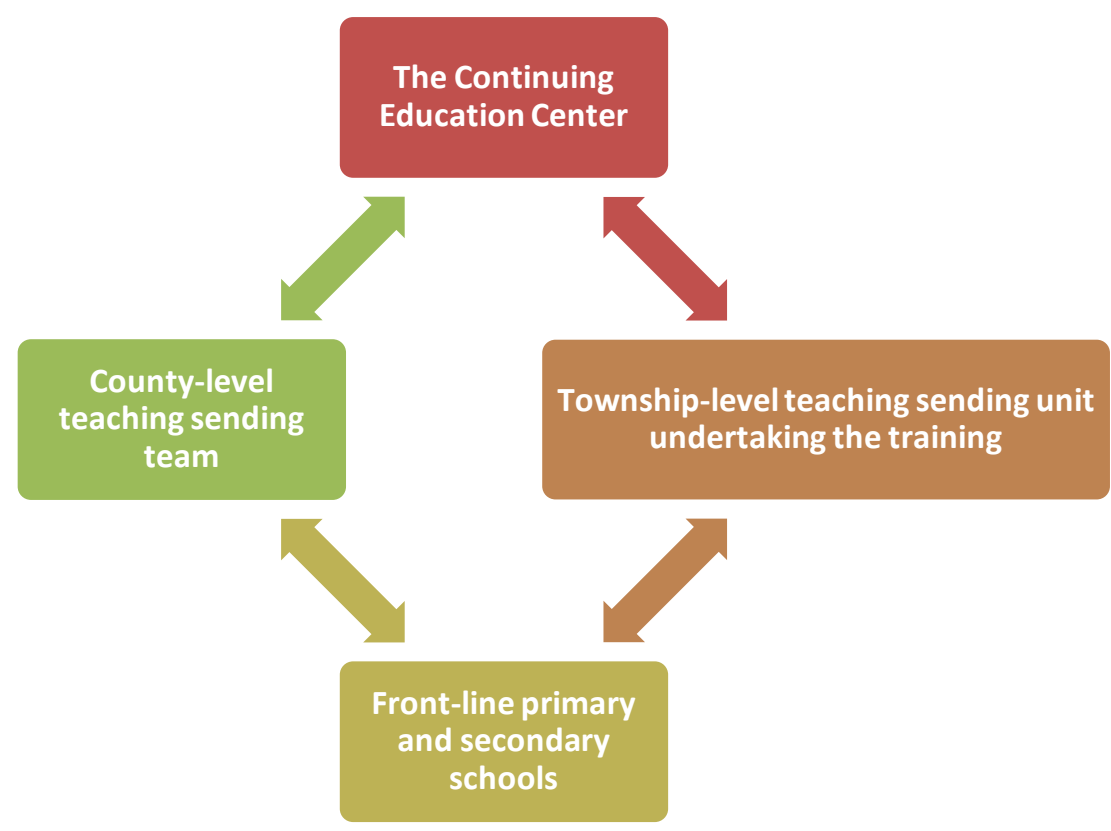

\section{Innovative Initiatives}

\subsection{Accurate demand research}

The demand research of the sending-teaching-to-the-countryside training will be conducted in the form of a special survey or comprehensive survey, involving development of questionnaires, directive distribution of questionnaires, seminars, individual interviews, use of WeChat, QQ and other means, to complete the Accurate List of Demand Research Elements for Teaching Sending.

\subsection{Strict monitoring of teaching sending process}

A sending-teaching-to-the-countryside training flow chart will be developed. Based on the flow chart, the links of demand research, grinding and studying classes, result demonstration, summary \& promotion and after-training reflection will be arranged. Led by the teaching research instructors, the teaching-sending teams will carry out the three-preparation and two-discussion activity aiming to the prominent problems in teaching, to determine the theme of teaching sending, and select the outstanding classes to show across the county.

The teaching sending will be implemented by modules, focusing on both theory and practice, to form a system, with the purpose of developing the strategies to solve the problems, and establish a new normal for the sending-teaching-to-the-countryside activity. Firstly, to carry out the teaching sending with full-scale design. The teaching-sending teams will design the overall program with an area as the unit, to ensure the activity is standard, consistent, orderly, progressive and well ended; Secondly, to carry out the teaching sending with problem tracking. The teaching-sending teams will conduct their work based on the problems, with the purpose of solving the problems; thirdly, to carry out the teaching sending with a guarantee mechanism. The teaching-sending teams will develop the teaching-sending system, coordinate the relationships, define the responsibilities and provide the correct guidance to ensure the effectiveness; and fourthly, to carry out the teaching sending with integrated resources. The teaching sending activities should be linked vertically and expanded horizontally, converging high-quality forces to solve the prominent problems; guaranteeing the results via process, and promoting the generation of new resources via the existing resources, showing the in-depth and sustainable characteristics. 


\section{Implementation Results}

\subsection{Promoting the teachers' personal professional development}

Training is not to make a dish, but to construct a pyramid. In the sending-teaching-to-the -countryside activity, the teaching-sending teams train the township and rural front-line teachers. The trainees attend more than 20 demonstrating and grinding classes, surrounding a training topic in each period. And then, they will apply what they have learned in the training into their teaching practice, which will benefit thousands of students. The experts, scholars, demonstration teachers and teaching research instructors will conduct the face-to-face demonstration diagnosis on the trainee teachers while the grinding and studying classes are being on. They will recommend the outstanding teachers to take part in the synchronous research class, grinding class, excellent selection of excellent teachers in the training to participate in the county-level subject teaching class competition. These initiatives will wake up teachers' internal driving force of growth, and they are the demand for teachers to development as the improvement of individual ability of teachers is the ultimate goal of training.

\subsection{Promoting the effective implementation of school-based training}

After training, all the township teaching research instructors will lead the teaching research groups in each school to use the sending-teaching-to-the-countryside mode to carry out the school-based research surrounding the Construction of Teaching Growth Community ("Teaching Strategies", "Making and Applying of Micro-class" and "Efficient Classroom ") and other topics. Meanwhile, with the "micro-class" competition, excellent case collection, sub-issue research and other teaching activities as an opportunity, they will track and guide, to make this form of teaching and research gradually become a normal.

\subsection{Promoting the trainers to grow together}

The top-down training system will drive the sending-teaching-to-the-countryside training, to maximize the effectiveness of teacher training activities. After the training, the training teachers gain knowledge while reaping the friendship, which is conductive to their mutual help and common progress both in work and in life.

The sending-teaching-to-the-countryside-training is developed from the expert point of view. The famous teachers' practical experience can inspire the personal minds, and provide meaningful classes, which will create the happiness unique to teachers and students. Through the practice and promotion, the "654" Sending-teaching-to-the-Countryside Training Mode will be able to further explore to the training path more suitable for the development of rural teachers, which is doubtlessly of great significance both in reality and in the long run.

\section{References}

[1] Zhang Kunxiang and Yang Guansuo Guiding out the subject course [M], Kunming: Yunnan People's Publishing House, July 2017.

[2] Gu Qizhou. Sending-teaching-to-the-countryside is not a show [J], Teaching and Management, 2015.14.

[3] Zheng Kaoju and Wang Jinfu. Analysis on implementation strategy of menu-type sending-teaching-to-the-countryside training mode [J], Journal of Yanbian Education College, Jan.2016. 